\title{
International investigation of outbreaks of foodborne disease
}

\author{
Public health responds to the globalisation of food
}

In 1992, the United States Institute of Medicine published a report entitled Emerging Infections: Microbial Threats to Health in the United States. ${ }^{1}$ The report, developed by an expert committee chaired by Drs Joshua Lederberg and Robert Shope, emphasised the fact that the world is truly a global village with respect to microbes. One factor is the change in the food industry. Foods, like many pathogens, are more likely than ever to cross national borders, and a single meal can combine products from many countries. In the United States and many other countries, importing of food from other parts of the world has increased greatly. ${ }^{2}$

One unintended consequence is that when food becomes contaminated the resulting outbreak can span continents. Indeed, Salmonella agona first spread around the world as a consequence of the use of contaminated Peruvian fish meal in chicken feed. ${ }^{3}$ More recent foodborne outbreaks of international scope include a multistate outbreak of Cyclospora cayetanenis infection in the United States and Canada related to raspberries imported from Guatemala, ${ }^{4}$ salmonellosis in the United States and several Scandinavian countries traced to alfalfa sprouts grown from imported seeds, ${ }^{56}$ shigellosis in northern Europe traced to lettuce from southern Europe, ${ }^{7}$ shigellosis in Europe traced to prawns from Asia, ${ }^{8}$ and cholera in the United States traced to fresh coconut milk imported from Asia. ${ }^{9}$ In this week's $B M \mathcal{F}$ (pp 1105, 1107) a two part report describes the recognition, investigation, and control of a large international outbreak of salmonellosis caused by a snack food produced in Israel that caused illness there and in at least two other countries (England and the United States). ${ }^{10}{ }^{11}$

In the past, foodborne outbreaks were often thought of as local events, affecting a group of people who all ate at one restaurant or attended one social event. These outbreaks are the easiest to detect because the victims themselves and the doctors they consult en masse can quickly perceive the clustered nature of the illnesses. Contamination of centrally produced foods that are widely distributed can lead to a diffuse outbreak, affecting people scattered over a wide area. More sophisticated public health surveillance is needed to detect this signal amid the background noise of many unrelated illnesses. For this reason, routine subtyping of some foodborne pathogens, coupled with analysis of surveillance data at a regional and national level, has become a powerful tool for detecting such outbreaks. For salmonella infections in England and Wales, routine serotyping and subtyping by phage susceptibility at the Public Health Laboratory Service, which celebrates its golden jubilee this year, has identified many outbreaks. When combined with epidemiological investigations, which have also become routine, this powerful pub- lic health approach can protect a nation's inhabitants and have an effect far beyond national borders.

Detection of a surge in one serotype is only the beginning. Systematic epidemiological interviews and comparison of reported exposures among affected people and a comparable group of healthy people can then define the critical differences in exposure. Once a sound epidemiological approach implicates a contaminated food, steps can be taken to remove it from the market to prevent additional cases. Detailed investigation of how the contamination could have occurred can lead to measures that will prevent similar episodes in the future. This productive collaboration between microbiologists, epidemiologists, and food scientists is the hallmark of successful investigations of foodborne outbreaks of disease.

Special challenges arise when the people affected, the investigators, and the food manufacturers are in different countries. For effective collaboration there needs to be a common goal and common methods. Salmonella serotyping and phage typing provides one common language for comparing strains from around the world. Comparable methods of national surveillance, such as reporting of the age and sex of individual patients, and similar methods of investigating outbreaks, are also critical to assembling the whole picture. International collaboration also provides new opportunities to increase the effectiveness of investigating outbreaks. In the outbreak of $S$ agona infections reported here, there were too few cases in the United States to detect the outbreak, though investigation of those few cases that did occur provided powerful confirmatory evidence that food was contaminated before it reached England. In Israel, ironically enough, there were almost too many cases. The exposure to the implicated snack food was so common among both cases and controls that the difference in exposure did not reach significance in the first Israeli case-control study, except that there was a clear increase in risk of illness associated with eating more of the snack food. Epidemiological investigations among groups that are universally exposed to the source are difficult at best, and sometimes establishing a dose-response relation is the best we can do. ${ }^{12}$ The combination of the epidemiological investigation in England, the helpful "outlier" cases in the United States, and the detailed epidemiological and plant investigations in Israel made the food supply of all three countries safer.

The $S$ agona outbreak provides several critically important lessons including the need for ongoing analyses of surveillance data, prompt epidemiological investigation, timely communication, close collaboration between epidemiologists and public health microbiologists, and prompt notification of colleagues in other countries potentially affected by distribution of a 
contaminated product. Clinicians also have an important part to play by alerting public health officials if they suspect a common source outbreak and ensuring that faecal specimens are submitted to a microbiology laboratory. Finally, the outbreak highlights the critical role of public health laboratories in disease control. These lessons are applicable to global strategies for addressing emerging infections. ${ }^{1314}$ The challenges presented by emerging infectious diseases demand that national and international organisations and agencies work closely together to strengthen global surveillance and capacity for response and to ensure timely communication when outbreaks with international implications are detected.

ROBERT V TAUXE

Chief

Foodborne and Diarrhoeal Diseases Branch,

Division of Bacterial and Mycotic Diseases,

National Center for Infectious Diseases

JAMES M HUGHES Director

National Center for Infectious Diseases,

Centers for Disease Control and Prevention,

Public Health Service

US Department of Health and Human Services,

Atlanta, Georgia 30333,

USA
1 Lederberg J, Shope RE, Oaks SC Jr, eds. Emerging infections: microbial threats to health in the United States. Washington, DC: National Academy Press, 1992.

2 Hedberg CW, MacDonald KL, Osterholm MT. Changing epidemiology of food-borne disease: a Minnesota perspective. Clin Infect Dis 1994;18:671-82.

3 Clark GM, Kaufmann AF, Gangarosa EJ, Thompson MA. Epidemiology of an international outbreak of Salmonella agona. Lancet 1973;ii:1-10.

Centers for Disease Control and Prevention. Update: outbreaks of Cyclospora cayetanensis infection-United States and Canada, 1996. MMWR 1996;45:611-2.

5 Mahon B, Ponka A, Hall W, Komatsu K, Beuchat L, Dietrick S. An international outbreak of salmonella infections caused by alfalfa sprouts grown from contaminated seed Abstract of the salmonella infections caused by alfalfa sprousts of the 36th Interscience Conference on Antimicrobial Agens

6 Van Beneden CA, Keene WE, Werker DH, King AS, Cieslak PR, Hedberg K, et al. A health food fights back: an international outbreak of Salmonella newport infections due to alfalf food fights back: an international outbreak of Salmonella newport infections due to alfalfa sprouts. Abstracts of the 36th Interscience Conference on Antimicrobial Agents
(ICAAC). New Orleans:American Society for Microbiology, 1996:258.

7 Frost JA, McEvoy MB, Bentley CA, Andersson Y, Rowe B. An outbreak of Shigella sonne infection associated with consumption of iceberg lettuce. Emerg Infect Dis 1995;1:26-9.

8 Mossel DAA, Kayser AM, Verhoef J, Zanen HC. De Shigella flexneri-epidemie random de jaarwisseling 1983/84: de les die daaruit geleerd moet worden. Ned Tijdschr Geneeskd 1985;129:886-8.

9 Taylor JL, Tuttle J, Pramukul T, O'Brien K, Barrett TJ, Jolbitado B, et al. An outbreak of cholera in Maryland associated with imported commercial frozen fresh coconut milk. $₹$ Infect Dis 1993;167:1330-5.

10 Killalea D, Ward LR, Roberts D, de Louvois J, Sufi F, Stuart JM, et al. An outbreak of Salmonella agona infection caused by contamination of a ready to eat savoury snack. I. England and the United States. BMf 1996;313:1105-7.

11 Shohat T, Green MS, Merom D, Gill ON, Reisfeld A, Matas A, et al. An international outbreak of Salmonella agona infection caused by contamination of a ready to eat savoury snack. II. of Salmonella agona infection
Israel. $B M 7$ 1996;313:1107-9.

12 Minz ED, Cartter ML, Hadler JL, Wassell JT, Zingeser JA, Tauxe RV. Dose response effects in Mintz ED, Cartter ML, Hadler JL, Wassell JT, Zingeser JA, Tauxe RV. Dose
an outbreak of Salmonella enteritidis. Epidemiol Infect 1994;112:13-23.

13 Lederberg J. Infectious disease-a threat to global health and security. $\mathscr{F} A M A$ 1996;276:417-9.

14 LeDuc JW. World Health Organization strategy for emerging infectious diseases. IAM $A$ 1996;275:318-20.

\section{Outbreaks of salmonellosis}

\section{Case control studies have their place, but their power should not be overestimated}

Knowing the serotype of a salmonella does not help in the treatment or prognosis of a case, nor is infection with different serotypes distinguishable clinically: all serotypes can cause serious disease, including septicaemia. ${ }^{1}$ Why then is it important for almost all 30000 or so salmonellas reported annually to Britain's Public Health Laboratory Service (PHLS) to undergo detailed identification, and for its Laboratory of Enteric Pathogens routinely to subdivide common serotypes into phage types that are irrelevant to patient management? One reason is to allow epidemiologists to use surveillance to identify linked cases. They can then trace sources and vehicles of infection, and curtail outbreaks. How has the case control method, as employed by Killelea et al and Shohat et al in this week's $B M Y,{ }^{23}$ helped achieve this?

Their papers ( $\mathrm{pp} 1105,1107$ ) describe the latest in a series of successful investigations of national and international outbreaks of salmonellosis ${ }^{4-8}$ which have two striking similarities: in all cases, the salmonella and the food vehicle were unusual. Such investigations are worth while and save money, ${ }^{9}$ but few cases are involved because most cases of salmonella seem to arise sporadically or from numerous small outbreaks.

Of the 29717 cases of salmonellosis reported to the PHLS in 1995, $28474(96 \%)$ were either part of a family outbreak or apparently sporadic. Here, the case-control method has limitations. It is more likely to succeed when an outbreak involves more than one household. Even then, few foods are identified compared with the total number of cases. Of the 68 outbreaks of salmonellosis involving more than one household in 1995 in which a food vehicle was suspected, statistical evidence from case-control and other studies (with or without microbial evidence) was advanced in support of this suspicion in 28 , involving 483 positive cases: $2 \%$ of the 1995 total (D Ross, personal communication). All 1995 data are provisional.

Epidemiological investigation of these outbreaks is nevertheless invaluable: it helps in local control and may provide clues to national problems. The approach has been more disappointing when applied to apparently sporadic infection.
This is not surprising: the case-control study is a tool to test specific hypotheses, and the causes of national increases of apparently sporadic cases are often multifactorial. The better defined the hypothesis, the better the chances of success of the case-control study: the rarer the salmonella, the more likely the formulation of a well defined hypothesis.

The salmonellas most commonly reported to the PHLS are $S$ enteritidis phage type 4 (pt4) and $S$ typhiumurium definitive type 104 (dt104). In 1995, these accounted for $42 \%$ and $12 \%$ of reports respectively. $S$ enteritidis pt 4 has been extensively investigated and is on the decline in Britain. Although a national case control study showed associations with poultry and egg products, ${ }^{10}$ it explained only $39 \%$ of cases, and results from well investigated outbreaks and surveillance data from animals and food were needed to conclude that the rise was due to eggs and poultry. ${ }^{11}$ The industry has made great efforts to control $S$ enteritidis $\mathrm{pt} 4$, and this type of salmonella is now on the decline in poultry as well as humans. ${ }^{12}$

$S$ typhimurium dt104 on the other hand is rising in humans, and its control poses problems. Reports to the PHLS have risen from 259 in 1990 to 3837 in $1995^{13}$ and are continuing to rise. As with $S$ enteritidis pt4, a case-control study of sporadic cases had limited effect in informing policy since it identified a range of foods, including pork sausages, chicken, and an unspecified meat paste, as well as contact with ill farm animals. ${ }^{14}$ Some veterinary evidence indicates farm animals, including cattle, as an important source, ${ }^{12}$ but the range of possible food vehicles makes specific recommendations to consumers more difficult than for $S$ enteritidis pt 4 .

$S$ typhimurium dt104 is a greater threat than $S$ enteritidis pt 4 because it is increasingly resistant to many antibiotics, including ciprofloxacin - $1 \%$ of human isolates in 1994 and $6 \%$ in $1995,{ }^{15}$ and there is no reason not to expect an accelerating increase in 1996. This is relevant to the management of the small number of patients with septicaemia. The rise in resistance has occurred concurrently with an increase in the use of ciprofloxacin by clini- 